\title{
The Coronavirus Family and Its existence in mammals for centuries
}

\author{
Ailis OCarroll, Ph.D
}

\section{Abstract}

Coronavirus (CoVs) have existed in mammals for centuries, historically, believed to only cause agriculturally devastating diseases in wild and domestic animals and the common cold type of symptoms in humans. Then in 2002, severe acute respiratory syndrome coronavirus (SARS-CoV) emerged from China resulting in the deaths of over 770 people. 10 years later, Middle East respiratory syndrome coronavirus (MERS-CoV) emerged from Saudi Arabia, with MERS-CoV continuing to cause outbreaks and as of Nov 2019 resulting in a total of 2,494 confirmed cases in 27 countries with 858 fatalities. With CoVs now understood to be widespread through mammals tested around the globe, another spill-over event was inevitable if no precautions and importance was put on understanding the risks of this zoonotic disease spread. To date, more than 200 novel coronaviruses have been found in bats and $\sim 35 \%$ of bat virome sequenced to date is composed of coronaviruses. Their and other mammals unique immune systems need to be the focus of future research with reports estimating mammal populations to harbour viruses in numbers up to 300 thousand. The SARS-CoV-2 pandemic is devastating with cases and deaths rising so rapidly that any number written would be out of date by time of publishing. Developing countries, war zones, refugee camps and those with a huge number of already immunocompromised patients such as the 25 million people in Africa living with HIV, will be decimated if the spread is not limited. Vaccines are beginning clinical trial phase and a huge global emphasis on interferon (IFN) research and drug development is underway. This will be necessary to control our unacceptable flu season fatalities and inevitable future pandemics. It is also crucial to understand that the most effective way to prevent viral zoonosis is to maintain the barriers between natural reservoirs and human society, in mind of the 'one health' concept. We are all interconnected, each biome, environment, climate, plant, animal, with our health and existence all deeply depend on each other. 
Coronavirus family (Coronaviridae; CoV) is the largest family within the Nidovirales order of viruses. This family is made up of two subfamilies called Letovirinae and Orthocoronavirinae. Then within this Orthocoronavirinae subfamily, there are four genera referred to as alphacoronavirus, betacoronavirus, gammacoronavirus and deltacoronavirus. Alphacoronaviruses and betacoronaviruses are found in mammals; causing respiratory and intestinal infections in humans and gastroenteritis in animals. The gammacoronaviruses and deltacoronaviruses are mainly found in birds ${ }^{1}$. These viruses are enveloped and have single stranded positive sense RNA genomes of 26 to 32 kilobases in size ${ }^{1,2}$. These genomes encode for structural, non-structural and accessory proteins, that vary between coronaviruses due to mutation and recombination of the viral genomes, and thus result in the survival of the viruses in different environments ${ }^{3-5}$. Historically, coronaviruses were believed to cause agriculturally devastating diseases in wild and domestic animals but only the common cold type of symptoms in humans. Then in 2002, severe acute respiratory syndrome coronavirus (SARS-CoV) emerged from China, lasting for 8 months, with 8090 confirmed human cases globally with 774 (9.5\%) fatalities ${ }^{6} .10$ years after SARS-CoV emerged, another highly pathogenic human coronavirus, Middle East respiratory syndrome coronavirus (MERS-CoV) emerged from Saudi Arabia, with MERS-CoV continuing to cause outbreaks and as of Nov 2019 resulting in a total of 2,494 confirmed cases in 27 countries with 858 fatalities $^{6}$. The common cold is caused by 4 strains of Coronavirus (HCoV-OC43, HCoV-NL63, $\mathrm{HCOV}-\mathrm{HKU1}$, and HCoV-229E) but these have been shown to progress to high-morbidity outcomes in the immunocompromised, where they result in pneumonia and bronchiolitis ${ }^{7}$.

The efficient human-to-human transmission of SARS-CoV came from the 'wet markets' in the Guangdong province of $\mathrm{China}^{8}$. It is now believed that mammals such as palm civets or pangolins being sold in the markets had been infected by CoV-infected bats ${ }^{9}$. It is thought that over 320,000 viruses have evolved to infect mammalian hosts ${ }^{10}$ and so mammals immune systems have also evolved to withstand such viral attack. These civets along with an unknown amount of other mammals are thought to have been infected with CoV potentially from fecal-oral transmission from the bats and then to each other. The virus then spread within the market civets and acquired further mutations before 'spilling-over' into humans, through the market workers. SARS-CoV and/or anti-SARS-CoV antibodies were found in these mammals such as the palm civets (Paguma larvata) and the animal handlers in a local market place ${ }^{8,11-15}$. Researchers found that many coronaviruses that are phylogenetically related to the SARS-CoV (referred to as SARSr-CoVs) were found in bats tested from the various provinces around China, as well as in European, African and Southeast Asian countries ${ }^{16-24}$. This data demonstrates that SARSr-CoVs have spread globally and have been in bats for an extremely long period of time, well before SARS-CoV emergence. A very interesting study done over 5 -years showed the coexistence of highly diverse SARSr-CoVs in the bat populations in one cave in the Yunnan province in China ${ }^{17,25,26}$. As this location is a diversity hot spot and the SARSr-CoVs here contain all the genetic diversity found in all other areas of China, the viral strains in this one area have all of the genetic elements needed to form the SARS-CoV virus and so is the probable area where SARS-CoV emerged from. Therefore, with no direct progenitor of SARS-CoV discovered in bat populations, even with 15 years of research and the discovery that RNA recombination is extremely common in coronaviruses, it is highly likely that SARS-CoV emerged recently from recombination of these bat SARSr-CoVs in this or a similar cave $^{27}$.

We will discuss the SARS-CoV-2 in this review but what we need to also focus on is that given the immense genetic diversity, the great amount of viruses that the bats and other mammals harbour, their close co-existence and frequent recombination, novel viruses will continue to emerge in the 
future and humanity needs to fully understand the science behind our beautifully balanced ecosystems and its influence on the spread of disease.

MERS-CoV surfaced in Saudi Arabia in 2012 with its spread still occurring and a fatality rate of $35 \%$. Dromedary camels were found to be the natural reservoir host for MERS-CoV with the seroprevalence rate in these camels ranging between $70 \%$ and $100 \%$ in the Arabian Peninsula and across Northern Africa ${ }^{28-33}$. Like the market workers in China, 16 out of 30 of the camel workers in Saudi Arabia that were tested in one study were shown to have MERS-CoV-specific CD8+ T cell responses and never had any history of the respiratory disease, showing that these humans who are in touch with animals (having the virus but being asymptomatic or with mild disease) pass the virus on to others ${ }^{34}$. Although the camels seemed to be the primary zoonotic reservoir for human transmission, research points towards bats being the ancestral reservoir host for MERS-CoV ${ }^{35,36}$. This coronavirus is a group $\mathrm{C}$ betacoronavirus, phylogenetically related to Bat CoVs belonging to bat species in the Vespertilionidae family. It is not known when MERS-CoV spread from bats to

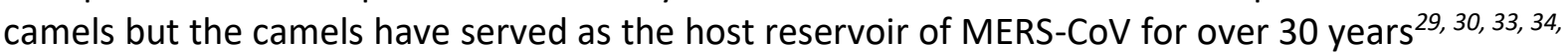
37.

It was found that the CoV virus' spike protein present in the bat version of the virus (HKU4) and that of MERS-CoV are extremely similar, with both using the human protein dipeptidyl-peptidase 4 (DPP4) to enter human cells ${ }^{38-40}$. The binding of this spike protein to human DPP4 could be thought of as a lock and key mechanism (although this is completely oversimplified). The binding of this key into a human lock dictates the critical determinant for the host range of the CoV. With SARS-CoV, electron microscopy studies have demonstrated that SARS-CoV S protein forms a shamrock-shaped trimer, with the RBD tip of each of the three head binding to human angiotensin-converting enzyme 2 (ACE2) ${ }^{41}$ as well as needing the cellular serine protease TMPRSS2 ${ }^{42-44}$, for virus entry into human cells ${ }^{45}, 46$. Different SARS-CoV strains have been found to vary in their binding affinities for human ACE2 and thus, their infectivity of human cells ${ }^{47,48}$. The epidemic strain taken from humans during the late phase of the 2002 to 2003 outbreak showed high affinity for human ACE2 and thus high infectivity in human cells, transmitting efficiently between humans ${ }^{49}$. While strain hcGd03 isolated from humans and civets in 2003-2004 had moderate affinity for human ACE2 and moderately infected humans; although it importantly did not transmit between people ${ }^{50}$. Therefore, it could not develop into an outbreak, unless further mutation occurred. As inhabitants living close to a bat cave in China showed antibodies against SARSr-CoV nucleocapsid protein, but did not exhibit any clinical symptoms of the disease. This demonstrated that 'suboptimal' versions of CoVs are continuously infecting humans from animal interactions and in this context rarely give rise to serious disease unless mutations occur to allow increased transmission and more pathogenic capacities.

The common cold can be caused by a variety of viruses, with similar symptoms presenting upon infection. HCoV-NL63 was identified in 2004 with an elderly patient with bronchiolitis and is now known to cause $1-9 \%$ of common colds annually and has circulated in humans for hundreds of years across the globe ${ }^{51,52}$. A North American bat, Perimyotis subflavus was found to have a recent common ancestor of HCoV-NL63 from $\sim 550$ years ago ${ }^{51}$. With similar sequences also found in bats in Africa ${ }^{53}$. HCoV-229E, another of the 4 known CoV strains that causes common cold like symptoms in humans, was first identified in 1967 and has also been circulating in the human population for years ${ }^{54}$.

As well as the coronaviruses that we have focussed on from a human disease perspective, other CoV have caused diseases that we are aware of due to their effect on human domestic animals such as transmissible gastroenteritis coronavirus (TGEV), porcine epidemic diarrhea virus (PEDV), 
avian infectious bronchitis virus (IBV) and swine acute diarrhea syndrome coronavirus (SADSCoV). PEDV caused a 3.21\% decrease in the U.S. pig livestock in less than two years (September 2012 to August 2014) $)^{55}$ and IBV caused the deaths of thousands of birds on poultry farms in Brazil $^{56}$. SADS-CoV outbreak resulted in the death of up to 25 thousand pigs across four farms in China from 2018. Viruses with up to $98 \%$ similarity to SADS-CoV were found in $9.8 \%$ of the bats that were sampled in the same region ${ }^{57}$. None of the human serum samples that were collected from farm workers were positive for antibodies against SADS-CoV ${ }^{57}$, implying that this strain of CoV was not able to infect humans.

\section{The Importance of Understanding Zoonotic Disease}

To date, more than 200 novel coronaviruses have been found in bats and $~ 35 \%$ of the viruses that bats contain (referred to as their virome) sequenced to date is composed of coronaviruses [20]. So why bats? Bats are an ancient and diverse group of mammals, that live in every continent apart from Antarctica. They make up almost $1 / 4$ of all mammalian diversity with more than 1300 species of bats in the order Chiroptera. This order is split into two suborders, Yinpterochiroptera and Yangochiroptera, diverging over 50 million years ago (m.y.a), with these suborders further grouped into families of bats ${ }^{58}$. Bats play a crucial role in the preservation of ecological balance. Without them there would be a serious decline in fruits, nuts and overall seed dispersal and plant pollination. Including bananas, mangoes, agave for tequila and cacao, over 300 fruit and nut species depend on bats for dispersal and more than 80 medicines come from the plants that bats aid in seed dispersal for. Bats also eat huge numbers of insects in every environment in which they inhabit and so without them there would be drastic increases in insect populations, resulting in surges of mosquito-spread disease, crop failure, economic damage and other human illness, if uncontrolled this would lead to devastating ecosystem collapse. $50 \%$ of the world's forests are said to be maintained by bats and as they make up a quarter of all mammals, without them we lose $25 \%$ of our global biodiversity ${ }^{59}$.

As aforementioned, bats are also home to incredibly large numbers of viruses from lyssaviruses (such as Rabies) to filoviruses (such as Marburg, Megala and Ebola), henipaviruses (such as Hendra and Nipah) to paramyxoviruses (such as SARS-CoV-1, SARS-CoV-2 and MERS) ${ }^{60,61}$. It is clear that many of the viruses that bats harbour are highly pathogenic to humans but intriguingly do not cause disease in the bats themselves. They, therefore, appear to act as the ultimate incubators, with a robust immune system that in effect "trains" up the virus to become as optimal as possible through mutation to enter and infect mammalian cells. Mammals cells have evolved conserved receptors (PRRs) that sense danger such as viruses, bacteria, fungus and parasites through binding to molecules referred to as pathogen associated molecular patterns (PAMPs) that they sense as 'foreign dangers' 62 . After viral infection, infected cells begin signalling events that cause the expression of antiviral and pro-inflammatory signalling molecules or cytokines ${ }^{62}$. One group of crucial antiviral cytokines are the interferons (IFNs). IFNs activate the expression of IFN-stimulated genes (ISGs) that inhibit virus replication through a multitude of different mechanisms ${ }^{63}$. Regulation of our inflammatory responses to viral infections is so important in order to prevent tissue damage with many severe virus infections causing our bodies to produce an excessive immune response and inflammation-associated pathology and fatalities. Bats, on the other hand, have evolved species-specific novel mechanisms to limit the virus-induced pro-inflammatory responses while maintaining type I IFN (and virus-specific antiviral genes that are induced independently of IFNs) in bat cells, ultimately controlling virus propagation. Many bat species have a dampened immune response towards DNA. The reduced ability of bat cells to detect exogenous and self-DNA is speculated to be a side-effect of the evolution of flight ${ }^{64}$. During flight, the body temperature of bats can rise dramatically to over $41^{\circ} \mathrm{C}$. High metabolic rates, along with 
elevated body temperatures, produce reactive oxygen species, which can cause DNA damage and release of DNA into the cytoplasm ${ }^{64}$. To overcome this, bats show evidence of positive selection in various genes involved with DNA repair, which had unintended consequences upon bats antiviral responses ${ }^{64}$. The selective pressure of DNA damage and release of self-DNA in the cytoplasm may have selected for the loss of certain cytosolic sensors of DNA in bat cells, to prevent immune responses occurring during flight ${ }^{65,66}$. As a reservoir host of a multitude viruses, bats have thus evolved to counteract the viruses proteins that cause immune-modulatory effects in humans. Bats adaptive immune system appears to have intriguing differences to our own, having a larger repertoire of germline genes encoding immunoglobulin variable (V), diversity (D) and joining $(\mathrm{J})$ segments, thus providing a larger number of antigen specificities for their naive $B$ cell receptors (BCRs) to use to detect and bind to virus with ${ }^{67}$. Put simply, the bat cells resist the virus, controlling its propagation, prevent their own immune system from over-reacting to the presence of the virus and its genome but do not clear the virus. Viruses then remain, persisting within the bats, adapting and recombining their genetic information. Whichever animal is unlucky enough to be closely related to bats and in close proximity, will become the 'spill-over host'. This creature will more than likely not have the immune capacity of the bat and thus will be overcome by viral proteins and their own inflammatory immune response to the virus. If not the poor civet, then the human that touches the civet.

This occurs with a multitude of other unrelated viruses such as Ebola virus and Marburg virus (a hemorrhagic virus related to Ebola), with a study published recently clearly demonstrating bat cells resistance and the virulence of the viruses that they harbour. Africa green monkey cells were exposed to viruses mimicking Ebola and Marburg virus and these were quickly overwhelmed, with cell death occurring due to the viruses. Bat cells from the Egyptian fruit bat (Rousettus aegyptiacus) and Australian black flying fox (Pteropus alecto) were challenged with the same viral load but completely resisted all viral onslaught and clear rapid IFN signalling defence was demonstrated ${ }^{68}$. These viruses could then co-exist with these cells, as in an organism. With there being up to 1400 global bat species and researchers focusing on 2 in this study it shows the immense diversity of viral content, persistence, adaption and responses available, all of which need to be studied and understood fully so as to mimic these responses for human prophylaxis and treatment to prevent future viral pandemics.

Bats are also not the only mammals that serve as reservoirs to deadly human zoonotic viruses. CoVs, for example, infect a wide variety of animals and are extremely common around the world ${ }^{69}$. However, data on the CoVs circulating in wildlife in specific areas are currently very limited. In Europe both alphacoronaviruses and betacoronaviruses have been found in bats from France, Germany, Italy, Netherlands to the UK, and surprisingly found in the vast majority of European rodents and rabbits tested ${ }^{70,71}$. The circulation of a range of CoVs within the same order and genus of mammals suggests the emergence of new CoVs by host switching ${ }^{70,72,73}$. There have been a multitude of intriguing findings such as European rodents only having alphacoronavirus and European wild rabbits found to have nucleic acid sequences close to the betacoronaviruses of domestic rabbits in China, while others had sequences highly similar alphacoronavirus to that in UK rodents ${ }^{74}, 75$. European hedgehogs were found to only have betacoronavirus and the prevalence of virus was much higher in hedgehogs than other species ${ }^{76}$. This study shows a snippet of the existence of only one of the evolving virus strains in a subset of all of the worlds wildlife populations. Other animals such as non-human primates, have led to viral outbreaks in 
humans such as the retroviruses. HIV and the disease of AIDS $^{77}$ is a clear example, since the recognition of the first cases in $1981^{78}$. HIV/AIDS has infected over 75 million of people worldwide and has caused the deaths of 32 million people, with up to 44 million people living with HIV/AIDS in 2018. Certain mammalian immune systems allow the adaption of viruses to cross the species barrier, the coexistence of multiple virus in these creatures is quite common and as we are mammals the viruses can usually enter and infect us using the same mechanisms. Our interactions with wildlife is normally limited when there is respect, however, we live in an overcrowded world, and whether in search of food, shelter, or to make a living, we have invaded new environments and disrupted ecosystems that have remained unchanged for thousands of years.

As it is becoming more and more evident that bats are unique in their ability to harbour virus, cover large distances, as the only mammals with this extent of flight and so inhabit most environments around the globe, awareness of this and all zoonotic disease risks need to be a priority. First and foremost, bats and all mammals should be respected (and no drastic measures should occur due to fear) because of their crucial role in the worlds ecosystems. Secondly, conversations need to be had between virologists, ecologists and biologists, as well as politicians, companies and the general public to uncover how to overcome one of the biggest problems our future generations will face : disease spread through humanity's impact on nature. Deforestation and the destruction of the food system on which bats depend will cause them to fly further and come into human inhabited areas, drastically increasing chances of spillover. Studies with Hendra virus have shown that reproductive and nutritional stress can increase levels of virus in little red flying fox populations (Pteropus scapulatus) ${ }^{64,79}$. Deforestation and other environmental and climate changes are causing these stresses. Other infections such as the infection of brown bats (Myotis lucifugus) with White-nose syndrome causing fungus (Pseudogymnoascus destructans) which has killed more than 6.5 million bats so far, has been shown to cause an increase in replication of a persistently infecting coronavirus ${ }^{80}$. We are beginning to understand how a seemingly small imbalance in one ecosystem can have drastic effects on the globe. Our impact on the environment has dramatically changed so many ecosystems with the extent only beginning to be felt. It is widely accepted that many viruses have existed in their natural reservoirs for a very long time but the seemingly sudden increase in spill-over events of viruses from natural hosts to humans and other animals is largely due to human activities, such as urbanisation and deforestation. It is completely irresponsible now that we are starting to realise the immensity of zoonotic disease spread, to not address these problems and implement a global plan of action. The most effective way to prevent viral zoonosis is to maintain the barriers between natural reservoirs and human society, in mind of the 'one health' concept ${ }^{81,} 82$. We are all interconnected, each biome, environment, climate, plant, animal, with our health and existence all deeply depend on each other.

\section{SARS-CoV-2 and viral outbreak, Now and Into the Future:}

In December 2019, a novel coronavirus, since named severe acute respiratory syndrome coronavirus 2 (SARS-CoV-2), emerged in Wuhan, China, resulting in a respiratory illness that the World Health Organization named 2019 novel coronavirus disease (COVID-19). The spread of this CoV outbreak was unprecedented and the world was not prepared, resulting in the SARS-CoV-2 epidemic becoming a pandemic on March $12^{\text {th }}$ 2020. It was first identified when 41 people presented with pneumonia of no clear cause, with people developing symptoms within 2 to 14 
days of contact with these infected patients ${ }^{83,}{ }^{84}$. Symptoms (in \% of cases from the WHO based on 56,000 lab cases) are fever ( $88 \%)$, dry cough (68\%), fatigue (38\%), phlegm (33\%), shortness of breath $(19 \%)$, muscle or joint pain $(15 \%)$, sore throat $(14 \%)$, headache $(14 \%)$, body chills $(11 \%)$, vomiting (5\%), stuffed nose (5\%) and diarrhoea (4\%). Those infected may be asymptomatic or have mild symptoms, with elderly patients and those who are immunocompromised at the most risk of serious symptoms and fatality. The cases and deaths are rising so rapidly that any number written would be out of date by time of publishing. Developing countries, war zones, refugee camps and those with a huge number of already immunocompromised patients such as the 25 million people in Africa living with HIV, will be decimated if we do not limit the spread.

Coronaviruses are spread through aerosol droplets expelled when an infected individual coughs or sneezes within a range of up to 2 metres with certain research stating 5-10metres, which can contaminate surrounding surfaces with potential survival upon these surfaces for up to 9 days ${ }^{85}$. Many viruses have been found upon further research to be passed through a faecal-oral route, as viral RNA can survive in human faeces with the possibility of spread. Viruses consist of protein and nucleic acids such as DNA or RNA and so to destroy a virus you must destroy / denature these organic compounds ${ }^{86}$. This can be done with heat and a variety of chemicals, such as $62-80 \%$ ethanol with ordinary soap being one of the most effective ${ }^{87}$. Soaps are mixtures of sodium or potassium salts of fatty acids which can be derived from oils or fats by reacting them with an alkali (such as sodium or potassium hydroxide) at $80^{\circ}-100{ }^{\circ} \mathrm{C}$ in a process known as saponification. The long hydrocarbon chain is non-polar and hydrophobic (repelled by water). The "salt" end of the soap molecule is ionic and hydrophilic (water soluble). Once they interact with the virus lipid bilayer, the organic compounds are "pulled apart" and the virus is destroyed.

There have been estimates for the basic reproduction number (the average number of people an infected person is likely to infect), ranging from 2 to 3 but with some reports stating above $4^{88,89}$. Direct comparisons are almost impossible due to spread being highly context and time specific. This is similar to SARS-CoV. Other recommendations include frequent washing of hands with soap and water, not touching one's eyes, nose or mouth unless the hands are clean, and covering the mouth fully when one coughs. People in high risk areas should take additional precautions even around people that are not displaying symptoms. Self-quarantining and social distancing is now beginning to take effect which will limit the spread.

Owing to the urgency of the epidemic, many scientific publishers have made scientific papers related to the outbreak open access. Some scientists have chosen to share their results quickly on preprint servers while archivists have created an illegal open access database of thousands of relevant papers. Labs, companies and countries are working around the clock on understanding the virus and developing a vaccine. As aforementioned the recent study indicates that SARS-CoV2 spread also depends on S protein and TMPRSS2 activity for entry and infections and the serine protease inhibitor camostat mesylate, which blocks TMPRSS2 activity ${ }^{90,}{ }^{91}$, has been approved in Japan for human use (for an unrelated indication but crucially demonstrating its safety and efficacy in humans). Therefore, this compound and related ones that will increase antiviral activity $^{92}$ are thus being considered for off-label treatment of SARS-CoV-2-infected patients. Moreover, experimental SARS vaccines, that include recombinant $S$ protein ${ }^{93}$ and inactivated virus $^{94}$, have been shown to induce neutralizing antibody responses.

The testing of the vaccines developed so far is now beginning with clinical trials. Vaccines have historically taken 2-5 years to develop and no single institution has the capacity or facilities to develop a vaccine by itself. There are so many more stages to the process than many people appreciate. Researchers need to fully understand the virus's characteristics and behaviour within 
humans. As it would be unethical to do this using actual humans, researchers use human cells to study the virus and to understand how it affects a whole organism, the closest thing humans have is other mammals and that is why animal models are developed and used. Researchers must demonstrate that potential vaccines are safe and can trigger the right immune response, without causing damage. Then pre-clinical animal testing of potential vaccines can begin, using the most optimal animal model. Our body's immune systems efficiently sense what is dangerous from what is safe but microorganisms and viruses have evolved to evade / hide themselves from our immune system surveillance. A vaccine contains a weakened, de-activated or partial form of the viral pathogen as well as other molecules that act as red-alert danger (antigen) signals/ alum priming our immune systems defences and antibodies to "remember" and "fight" anything that is sensed with these molecules. The vaccine won't cause disease, because the weakened version can no longer copy itself to release new virus inside the body but the antibodies "memory" will create immunity against future infections with the same type of virus. As well as vaccinating you, vaccinations also help protect people who can't be vaccinated. These might be babies who are too young to receive a vaccine or people who are too ill or too old to be vaccinated. When enough people in a community are vaccinated against a particular contagious disease, there's little opportunity for that disease to spread from person to person. Doctors call this type of community protection "herd immunity" 95.

Vaccines that successfully pass pre-clinical testing on animal models can then be used by other institutions with the capacity to run human trials. There are a huge number of crucial tests needed to be undertaken regarding how the vaccine affects the immense variety of humans that make up our global population- ethnicity, age, sex, how other drugs, previous infections and even food impacts the vaccine, how stable it is, how strong the immune response is, how many rounds of vaccination are needed for full immunity..the list goes on. Finally, if the vaccine is found to be safe and effective, it will need to pass the necessary regulatory approvals, a cost-effective way of making the vaccine will need to be in place and an immense global plan on how to role it out over the globe, all needs to be put in place before the final vaccine is ready for delivery. Each of these steps in the vaccine development pipeline faces huge challenges and nothing can be overlooked with such lives at stake. The fastest timescale will be months up to over a year.

However, working together we will get a hold of this virus and a vaccine will stop the spread and allow the pandemic to come to an end. For now we just need to limit the spread while it is being developed. For the future, however, we need a better approach. Viruses are so varied, and as aforementioned there could be up to over 300,000 out there that could potentially infect us ${ }^{10}$. We cannot create a vaccine for each of them. However what is common to us all is how our bodies fight back. Our immune response and in particular our IFN response. SARS-CoV genes/ ORFs namely nsp1, nsp3, ORF3 and ORF6 were shown to directly and indirectly inhibit specific human genes and proteins tailored for preventing and fighting a viral attack using the IFN response and so this gives us a huge clue as to what the biggest threat to the virus is ${ }^{96}$. For a virus to have evolved to prevent the efficient working of these proteins, the focus of the virus is on preventing our IFN release.

Our interferon anti-viral response needs to be focused on like never before. Bats unique IFN responses allow them to remain unaffected by viral infections ${ }^{97}$. We need to completely understand our response and how we can potentially improve it through the use of various drugs. Crucial studies have shown how SARS viral infection was inhibited and cleared with the drug IFNalfacon-1, which is a synthetic form of IFN ${ }^{98,99}$. If this SARS-CoV-2 continues to mutate, specific vaccines may not work and researchers would have to start from scratch. Specific antiviral drugs 
and vaccines are extremely useful but a multipronged approach is needed with huge funding going into IFN drug development, that can be used prophylactically (on healthy and at risk patients before they get sick) during flu season and to treat emerging viral outbreaks rapidly. VP35 and VP24 are Ebola proteins that specifically target IFN products ${ }^{100,101}$. The polymerase cofactor,VP35, antagonizes IFN signaling and the production of ISGs in several unique ways. The minor matrix protein, VP24, also functions as an IFN antagonist by reducing host cell sensitivity to IFNs and inhibiting expression of ISGs. ISGs are antiviral effectors that restrict infection in various ways. VP24 is able to mitigate antiviral effects of both type I and type II IFNs by blocking signal transduction through IFN receptors ${ }^{100,101}$. Novel studies indicate that IFN- $\beta$ is a potent inhibitor of Ebola virus, contributing to the decision to conduct a clinical trial of IFN-ß treatment for Ebola virus disease in Guinea, with have been extremely promising results ${ }^{102}$. Nebulized IFNa2b and drugs such as Arbidol/ Umifenovir are being used in trials on COVID-19 patients. It is now also being reported that doctors and other medical staff are prophylactically taking this IFN.

Viruses target IFN pathways for a reason. They work. We need to up the arms race with this information and efficiently control our IFN levels, just as bats and other mammals have evolved to do. Whether it is using IFN activators instead of / with alum in vaccines or as a set drug, this is the future for viral treatment and with the present climate and outbreaks this needs to be focused on and funded now. Drugs such as Arbidol/ Umifenovir also need to be of focus. Umifenovir, for example, inhibits membrane fusion, preventing contact between the virus (viral envelope) and target host cells (cell membrane). This prevents viral entry to the target cell, and therefore protects it from infection ${ }^{103}$. The drug induces IFN-production, stimulates a humoral immune response and stimulates the phagocytic function of macrophages ${ }^{104}$. It is used to treat influenza, is being investigated as a candidate drug for treatment of hepatitis $\mathrm{C}^{105}$ and more recently, studies indicate that umifenovir also has in vitro effectiveness at preventing entry of human herpes virus $^{106}$, Hepatitis B, poliovirus, Tacaribe arenavirus and Ebolavirus strains ${ }^{107,}$ 108, In February 2020, Li Lanjuan, an expert of the National Health Commission of China, proposed using Arbidol (umifenovir) together with darunavir as a potential treatment during the 2019-20 coronavirus pandemic. Chinese experts claim that preliminary tests had shown that arbidol and darunavir could inhibit replication of the virus ${ }^{109}$.

Finally I believe that after this outbreak we also need to start the discussion on how unacceptable the levels of flu are globally and as this coronavirus strain will potentially join the list that reemerge each flu season. A recent study estimated an average of 389000 (uncertainty range 294 000-518 000) respiratory deaths were associated with influenza globally each year during the study period, corresponding to $2 \%$ of all annual respiratory deaths. Of these, $67 \%$ were among people 65 years and older ${ }^{110}$. For people $<65$ years, higher baseline respiratory mortality, lower level of access to health care and seasons dominated by the $A(H 1 N 1) p d m 09$ subtype were associated with higher influenza-associated mortality, while lower level of socio-demographic development and $\mathrm{A}(\mathrm{H} 3 \mathrm{~N} 2)$ dominance was associated with higher influenza mortality in adults $\geq 65$ years. Each flu season is distinctive such as the $2019-2020$ season. It had been usual to have a dominant influenza strain throughout the entire season. While last year, there was two seasons or two waves of viral strains. Most people who were infected with the flu in late autumn/ early winter had a strain called H1N1, but the dominant flu strain changed further into the season, and by late winter/early spring, the strain known as H3N2 showed up and started infecting larger numbers of people. Not only did this create a second wave of flu infections, but many of those cases were more severe. H3N2 was a surprise to medical experts who study the flu and use forecasts to formulate the annual vaccine that protects against the flu strains that are expected to be circulating. Last year's vaccine was not formulated to protect against H3N2. The flu vaccine 
for the 2019-2020 season has been formulated to protect against both H1N1 and H3N2, the two strains that dominated last year's flu season, as well as other strains that are currently circulating. As we have discussed, vaccines take time to generate and decisions about which flu strains will be included in the vaccine each year have to be made well before flu researchers know which strains will be dominant during the upcoming season, with this often changing rapidly. This being said, until we have an immense repertoire of prophylactic immune enhancing drugs, the vaccine still offers the greatest chance at protection. It reduces your flu risk as the flu vaccine is a combination vaccine, meaning that it's formulated to protect against three to four different strains of the flu at once - and when the vaccine is a good match with the circulating viruses, it will help prevent you from getting the flu. It reduces flu duration and severity as even if you get vaccinated and still get the flu, the vaccine will help reduce the length of the illness and the severity of your symptoms. It also reduces the chance that you'll need to be hospitalised or develop serious health complications, like pneumonia. Above all else it reduces the spread of the flu. If everyone in your community receives the flu vaccine, herd immunity has been put in place, your community is protecting those who are not eligible for the vaccine, children under six months, and the elderly populations who are at an increased risk of flu-related complications. Up to 50 million illnesses, 23 million medical visits, 620 thousand hospitalisations and up to 52 thousands deaths in just the 2019-2020 in the US Flu season alone was estimated by the CDC.

This is not ok and should have been a huge priority of the world for the past decade. This along with the novel outbreaks, driven by globalisation and increased population densities impacting wildlife interactions and climate change, the time has come to get on top of the viruses that we co-habit the world with. We do not understand even the most notable viruses of our time. From the time the Ebola virus (EBOV) first emerged in the small village of Yambuku, Democratic Republic of Congo (named Zaire at the time), it has captured the attention of the world. The extreme symptoms observed in severe cases of Ebola hemorrhagic fever (EHF) coupled with the high mortality rate ( $88 \%$ in the Yambuku outbreak) have established EBOV as among the most terrifying emerging viruses with more than 28000 individuals became infected, and at least 11 000 people having died ${ }^{111}$. The West African outbreak demonstrates that viruses such as EBOV are serious emerging pathogenic threats, of an entirely different spread pattern to virus outbreaks such as the influenza or coronaviruses and can be contained and controlled much more easily in developed countries but are devastating in war-torn countries and communities lacking public health infrastructure. Ebola was just recently found to survive for up to 40months in "cured' survivors bodily fluids such as semen, with maximum duration now unknown ${ }^{112,113}$. Now evidence of persistent infections in immune-privileged sites such as eyes and testes and chronic conditions such as headaches, fatigue, and visual impairment, are being described as post-Ebola syndrome ${ }^{114,115}$.

It is clear that very little is known about the mechanisms underlying viral persistence or pathology and the sudden emergence of this outbreak is a critical reminder that even now, our knowledge of how viruses interact with their hosts on the molecular, cellular, and organismal levels is still rudimentary. Developing a finely detailed understanding of emerging viral biology and viruses that infect our closest mammals in the context of both susceptible hosts and reservoir species will be critical to containing future outbreaks and to developing immunization strategies or therapeutics that target host processes rather than viral proteins. Certain viruses have the upper hand on our immune systems but with increased antiviral responses we will be able to use nature and our built-in defences to the optimal level needed to withstand both known and unknown attacks. So let's curb the spread of this virus through self-quarantine, social distancing, hand 
sanitisation until vaccine introduction, then focus on a global plan of action for IFN, antiviral and immune system boosting drug discovery and development, as well as a one-health plan of action to implement serious respect for nature and for the future health of our planet.

[1] Woo, P. C., Huang, Y., Lau, S. K., and Yuen, K.-Y. (2010) Coronavirus genomics and bioinformatics analysis, Viruses 2, 1804-1820.

[2] Coleman, C. M., and Frieman, M. B. (2014) Coronaviruses: important emerging human pathogens, Journal of virology 88, 5209-5212.

[3] Liu, D. X., Fung, T. S., Chong, K. K.-L., Shukla, A., and Hilgenfeld, R. (2014) Accessory proteins of SARS-CoV and other coronaviruses, Antiviral research 109, 97-109.

[4] Narayanan, K., Huang, C., and Makino, S. (2008) SARS coronavirus accessory proteins, Virus research 133, 113-121.

[5] Yang, Y., Zhang, L., Geng, H., Deng, Y., Huang, B., Guo, Y., Zhao, Z., and Tan, W. (2013) The structural and accessory proteins $\mathrm{M}, \mathrm{ORF} 4 \mathrm{a}, \mathrm{ORF} 4 \mathrm{~b}$, and ORF 5 of Middle East respiratory syndrome coronavirus (MERS-CoV) are potent interferon antagonists, Protein \& cell 4, 951-961.

[6] Al-Tawfiq, J. A., Zumla, A., and Memish, Z. A. (2014) Travel implications of emerging coronaviruses: SARS and MERS-CoV, Travel medicine and infectious disease 12, 422-428.

[7] Lim, Y. X., Ng, Y. L., Tam, J. P., and Liu, D. X. (2016) Human coronaviruses: a review of virus-host interactions, Diseases 4, 26.

[8] Guan, Y., Zheng, B., He, Y., Liu, X., Zhuang, Z., Cheung, C., Luo, S., Li, P., Zhang, L., and Guan, Y. (2003) Isolation and characterization of viruses related to the SARS coronavirus from animals in southern China, Science 302, 276-278.

[9] Kuehn, B. M. (2013) More evidence emerges that bats may have spread SARS, JAMA 310, 21382138.

[10] Anthony, S. J., Epstein, J. H., Murray, K. A., Navarrete-Macias, I., Zambrana-Torrelio, C. M., Solovyov, A., Ojeda-Flores, R., Arrigo, N. C., Islam, A., and Khan, S. A. (2013) A strategy to estimate unknown viral diversity in mammals, MBio 4, e00598-00513.

[11] Kan, B., Wang, M., Jing, H., Xu, H., Jiang, X., Yan, M., Liang, W., Zheng, H., Wan, K., and Liu, Q. (2005) Molecular evolution analysis and geographic investigation of severe acute respiratory syndrome coronavirus-like virus in palm civets at an animal market and on farms, Journal of virology 79, 11892-11900.

[12] Tu, C., Crameri, G., Kong, X., Chen, J., Sun, Y., Yu, M., Xiang, H., Xia, X., Liu, S., and Ren, T. (2004) Antibodies to SARS coronavirus in civets, Emerging infectious diseases 10, 2244.

[13] Wang, M., Xu, H.-F., Zhang, Z.-B., Zou, X.-Z., Gao, Y., Liu, X.-N., Lu, E.-J., Liang, C.-Y., Pan, B.-Y., and $\mathrm{Wu}, \mathrm{S} .-\mathrm{J}$. (2004) Analysis on the risk factors of severe acute respiratory syndromes coronavirus infection in workers from animal markets, Zhonghua liu xing bing xue za zhi= Zhonghua liuxingbingxue zazhi 25, 503.

[14] Xu, H., Wang, M., Zhang, Z., Zou, X., Gao, Y., Liu, X., Lu, E., Pan, B., Wu, S., and Yu, S. (2004) An epidemiologic investigation on infection with severe acute respiratory syndrome coronavirus in wild animals traders in Guangzhou, Zhonghua yu fang yi xue za zhi [Chinese journal of preventive medicine] 38, 81-83.

[15] Song, H.-D., Tu, C.-C., Zhang, G.-W., Wang, S.-Y., Zheng, K., Lei, L.-C., Chen, Q.-X., Gao, Y.-W., Zhou, H.-Q., and Xiang, H. (2005) Cross-host evolution of severe acute respiratory syndrome coronavirus in palm civet and human, Proceedings of the National Academy of Sciences 102, 2430-2435.

[16] Lau, S. K., Woo, P. C., Li, K. S., Huang, Y., Tsoi, H.-W., Wong, B. H., Wong, S. S., Leung, S.-Y., Chan, K.-H., and Yuen, K.-Y. (2005) Severe acute respiratory syndrome coronavirus-like virus in Chinese horseshoe bats, Proceedings of the National Academy of Sciences 102, 14040-14045. 
[17] Hu, B., Zeng, L.-P., Yang, X.-L., Ge, X.-Y., Zhang, W., Li, B., Xie, J.-Z., Shen, X.-R., Zhang, Y.-Z., and Wang, N. (2017) Discovery of a rich gene pool of bat SARS-related coronaviruses provides new insights into the origin of SARS coronavirus, PLoS pathogens 13.

[18] Lacroix, A., Duong, V., Hul, V., San, S., Davun, H., Omaliss, K., Chea, S., Hassanin, A., Theppangna, W., and Silithammavong, S. (2017) Genetic diversity of coronaviruses in bats in Lao PDR and Cambodia, Infection, Genetics and Evolution 48, 10-18.

[19] Li, W., Shi, Z., Yu, M., Ren, W., Smith, C., Epstein, J. H., Wang, H., Crameri, G., Hu, Z., and Zhang, H. (2005) Bats are natural reservoirs of SARS-like coronaviruses, Science 310, 676-679.

[20] Drexler, J. F., Gloza-Rausch, F., Glende, J., Corman, V. M., Muth, D., Goettsche, M., Seebens, A., Niedrig, M., Pfefferle, S., and Yordanov, S. (2010) Genomic characterization of severe acute respiratory syndrome-related coronavirus in European bats and classification of coronaviruses based on partial RNA-dependent RNA polymerase gene sequences, Journal of virology 84, 11336-11349.

[21] Rihtarič, D., Hostnik, P., Steyer, A., Grom, J., and Toplak, I. (2010) Identification of SARS-like coronaviruses in horseshoe bats (Rhinolophus hipposideros) in Slovenia, Archives of virology 155, 507-514.

[22] Yuan, J., Hon, C.-C., Li, Y., Wang, D., Xu, G., Zhang, H., Zhou, P., Poon, L. L., Lam, T. T.-Y., and Leung, F. C.-C. (2010) Intraspecies diversity of SARS-like coronaviruses in Rhinolophus sinicus and its implications for the origin of SARS coronaviruses in humans, Journal of general virology 91 , 1058-1062.

[23] He, B., Zhang, Y., Xu, L., Yang, W., Yang, F., Feng, Y., Xia, L., Zhou, J., Zhen, W., and Feng, Y. (2014) Identification of diverse alphacoronaviruses and genomic characterization of a novel severe acute respiratory syndrome-like coronavirus from bats in China, Journal of virology 88, 70707082.

[24] Gouilh, M. A., Puechmaille, S. J., Gonzalez, J.-P., Teeling, E., Kittayapong, P., and Manuguerra, J.C. (2011) SARS-Coronavirus ancestor's foot-prints in South-East Asian bat colonies and the refuge theory, Infection, Genetics and Evolution 11, 1690-1702.

[25] Ge, X.-Y., Li, J.-L., Yang, X.-L., Chmura, A. A., Zhu, G., Epstein, J. H., Mazet, J. K., Hu, B., Zhang, W., and Peng, C. (2013) Isolation and characterization of a bat SARS-like coronavirus that uses the ACE2 receptor, Nature 503, 535-538.

[26] Wang, M.-N., Zhang, W., Gao, Y.-T., Hu, B., Ge, X.-Y., Yang, X.-L., Zhang, Y.-Z., and Shi, Z.-L. (2016) Longitudinal surveillance of SARS-like coronaviruses in bats by quantitative real-time PCR, Virologica Sinica 31, 78-80.

[27] Lai, M. M., and Cavanagh, D. (1997) The molecular biology of coronaviruses, In Advances in virus research, pp 1-100, Elsevier.

[28] Falzarano, D., Kamissoko, B., de Wit, E., Maïga, O., Cronin, J., Samaké, K., Traoré, A., Milne-Price, S., Munster, V. J., and Sogoba, N. (2017) Dromedary camels in northern Mali have high seropositivity to MERS-CoV, One Health 3, 41-43.

[29] Müller, M. A., Corman, V. M., Jores, J., Meyer, B., Younan, M., Liljander, A., Bosch, B.-J., Lattwein, E., Hilali, M., and Musa, B. E. (2014) MERS coronavirus neutralizing antibodies in camels, Eastern Africa, 1983-1997, Emerging infectious diseases 20, 2093.

[30] Reusken, C. B., Messadi, L., Feyisa, A., Ularamu, H., Godeke, G.-J., Danmarwa, A., Dawo, F., Jemli, M., Melaku, S., and Shamaki, D. (2014) Geographic distribution of MERS coronavirus among dromedary camels, Africa, Emerging infectious diseases 20, 1370.

[31] Deem, S. L., Fèvre, E. M., Kinnaird, M., Browne, A. S., Muloi, D., Godeke, G.-J., Koopmans, M., and Reusken, C. B. (2015) Serological evidence of MERS-CoV antibodies in dromedary camels (Camelus dromedaries) in Laikipia County, Kenya, PLoS One 10.

[32] Alexandersen, S., Kobinger, G., Soule, G., and Wernery, U. (2014) Middle East respiratory syndrome coronavirus antibody reactors among camels in Dubai, United Arab Emirates, in 2005, Transboundary and emerging diseases 61, 105-108. 
[33] Reusken, C. B., Haagmans, B. L., Müller, M. A., Gutierrez, C., Godeke, G.-J., Meyer, B., Muth, D., Raj, V. S., Smits-De Vries, L., and Corman, V. M. (2013) Middle East respiratory syndrome coronavirus neutralising serum antibodies in dromedary camels: a comparative serological study, The Lancet infectious diseases 13, 859-866.

[34] Alshukairi, A. N., Zheng, J., Zhao, J., Nehdi, A., Baharoon, S. A., Layqah, L., Bokhari, A., Al Johani, S. M., Samman, N., and Boudjelal, M. (2018) High prevalence of MERS-CoV infection in camel workers in Saudi Arabia, MBio 9, e01985-01918.

[35] Memish, Z. A., Mishra, N., Olival, K. J., Fagbo, S. F., Kapoor, V., Epstein, J. H., AlHakeem, R., Durosinloun, A., Al Asmari, M., and Islam, A. (2013) Middle East respiratory syndrome coronavirus in bats, Saudi Arabia, Emerging infectious diseases 19, 1819.

[36] Anthony, S. J., Gilardi, K., Menachery, V., Goldstein, T., Ssebide, B., Mbabazi, R., Navarrete-Macias, I., Liang, E., Wells, H., and Hicks, A. (2017) Further evidence for bats as the evolutionary source of Middle East respiratory syndrome coronavirus, MBio 8, e00373-00317.

[37] Corman, V. M., Jores, J., Meyer, B., Younan, M., Liljander, A., Said, M. Y., Gluecks, I., Lattwein, E., Bosch, B.-J., and Drexler, J. F. (2014) Antibodies against MERS coronavirus in dromedary camels, Kenya, 1992-2013, Emerging infectious diseases 20, 1319.

[38] Lau, S. K., Zhang, L., Luk, H. K., Xiong, L., Peng, X., Li, K. S., He, X., Zhao, P. S.-H., Fan, R. Y., and Wong, A. C. (2018) Receptor usage of a novel bat lineage $c$ betacoronavirus reveals evolution of Middle East respiratory syndrome-related coronavirus spike proteins for human dipeptidyl peptidase 4 binding, The Journal of infectious diseases 218, 197-207.

[39] Wang, Q., Qi, J., Yuan, Y., Xuan, Y., Han, P., Wan, Y., Ji, W., Li, Y., Wu, Y., and Wang, J. (2014) Bat origins of MERS-CoV supported by bat coronavirus HKU4 usage of human receptor CD26, Cell host \& microbe 16, 328-337.

[40] Luo, C.-M., Wang, N., Yang, X.-L., Liu, H.-Z., Zhang, W., Li, B., Hu, B., Peng, C., Geng, Q.-B., and Zhu, G.-J. (2018) Discovery of novel bat coronaviruses in south China that use the same receptor as Middle East respiratory syndrome coronavirus, Journal of virology 92, e00116-00118.

[41] Li, W., Moore, M. J., Vasilieva, N., Sui, J., Wong, S. K., Berne, M. A., Somasundaran, M., Sullivan, J. L., Luzuriaga, K., and Greenough, T. C. (2003) Angiotensin-converting enzyme 2 is a functional receptor for the SARS coronavirus, Nature 426, 450-454.

[42] Glowacka, I., Bertram, S., Müller, M. A., Allen, P., Soilleux, E., Pfefferle, S., Steffen, I., Tsegaye, T. S., He, Y., and Gnirss, K. (2011) Evidence that TMPRSS2 activates the severe acute respiratory syndrome coronavirus spike protein for membrane fusion and reduces viral control by the humoral immune response, Journal of virology 85, 4122-4134.

[43] Matsuyama, S., Nagata, N., Shirato, K., Kawase, M., Takeda, M., and Taguchi, F. (2010) Efficient activation of the severe acute respiratory syndrome coronavirus spike protein by the transmembrane protease TMPRSS2, Journal of virology 84, 12658-12664.

[44] Shulla, A., Heald-Sargent, T., Subramanya, G., Zhao, J., Perlman, S., and Gallagher, T. (2011) A transmembrane serine protease is linked to the severe acute respiratory syndrome coronavirus receptor and activates virus entry, Journal of virology 85, 873-882.

[45] Li, F., Berardi, M., Li, W., Farzan, M., Dormitzer, P. R., and Harrison, S. C. (2006) Conformational states of the severe acute respiratory syndrome coronavirus spike protein ectodomain, Journal of virology 80, 6794-6800.

[46] Yuan, Y., Cao, D., Zhang, Y., Ma, J., Qi, J., Wang, Q., Lu, G., Wu, Y., Yan, J., and Shi, Y. (2017) CryoEM structures of MERS-CoV and SARS-CoV spike glycoproteins reveal the dynamic receptor binding domains, Nature communications 8, 15092.

[47] Li, W., Zhang, C., Sui, J., Kuhn, J. H., Moore, M. J., Luo, S., Wong, S. K., Huang, I. C., Xu, K., and Vasilieva, N. (2005) Receptor and viral determinants of SARS-coronavirus adaptation to human ACE2, The EMBO journal 24, 1634-1643.

[48] Qu, X.-X., Hao, P., Song, X.-J., Jiang, S.-M., Liu, Y.-X., Wang, P.-G., Rao, X., Song, H.-D., Wang, S.-Y., and Zuo, Y. (2005) Identification of two critical amino acid residues of the severe acute 
respiratory syndrome coronavirus spike protein for its variation in zoonotic tropism transition via a double substitution strategy, Journal of Biological Chemistry 280, 29588-29595.

[49] Consortium, C. S. M. E. (2004) Molecular evolution of the SARS coronavirus during the course of the SARS epidemic in China, Science 303, 1666-1669.

[50] Liang, G., Chen, Q., Xu, J., Liu, Y., Lim, W., Peiris, J., Anderson, L. J., Ruan, L., Li, H., and Kan, B. (2004) Laboratory diagnosis of four recent sporadic cases of community-acquired SARS, Guangdong Province, China, Emerging infectious diseases 10, 1774.

[51] Huynh, J., Li, S., Yount, B., Smith, A., Sturges, L., Olsen, J. C., Nagel, J., Johnson, J. B., Agnihothram, S., and Gates, J. E. (2012) Evidence supporting a zoonotic origin of human coronavirus strain NL63, Journal of virology 86, 12816-12825.

[52] Pyrc, K., Dijkman, R., Deng, L., Jebbink, M. F., Ross, H. A., Berkhout, B., and Van der Hoek, L. (2006) Mosaic structure of human coronavirus NL63, one thousand years of evolution, Journal of molecular biology 364, 964-973.

[53] Tao, Y., Shi, M., Chommanard, C., Queen, K., Zhang, J., Markotter, W., Kuzmin, I. V., Holmes, E. C., and Tong, S. (2017) Surveillance of bat coronaviruses in Kenya identifies relatives of human coronaviruses NL63 and 229E and their recombination history, Journal of virology 91, e0195301916.

[54] Mclntosh, K., Dees, J. H., Becker, W. B., Kapikian, A. Z., and Chanock, R. M. (1967) Recovery in tracheal organ cultures of novel viruses from patients with respiratory disease, Proceedings of the National Academy of Sciences of the United States of America 57, 933.

[55] Schulz, L. L., and Tonsor, G. T. (2015) Assessment of the economic impacts of porcine epidemic diarrhea virus in the United States, Journal of animal science 93, 5111-5118.

[56] Colvero, L., Villarreal, L., Torres, C., and Brañdo, P. (2015) Assessing the economic burden of avian infectious bronchitis on poultry farms in Brazil, Rev. Sci. Tech 34, 993-999.

[57] Zhou, P., Fan, H., Lan, T., Yang, X.-L., Shi, W.-F., Zhang, W., Zhu, Y., Zhang, Y.-W., Xie, Q.-M., and Mani, S. (2018) Fatal swine acute diarrhoea syndrome caused by an HKU2-related coronavirus of bat origin, Nature 556, 255-258.

[58] Lei, M., and Dong, D. (2016) Phylogenomic analyses of bat subordinal relationships based on transcriptome data, Scientific reports 6, 27726.

[59] Ratto, F., Simmons, B. I., Spake, R., Zamora-Gutierrez, V., MacDonald, M. A., Merriman, J. C., Tremlett, C. J., Poppy, G. M., Peh, K. S. H., and Dicks, L. V. (2018) Global importance of vertebrate pollinators for plant reproductive success: a meta-analysis, Frontiers in Ecology and the Environment 16, 82-90.

[60] Fisher, C. R., Streicker, D. G., and Schnell, M. J. (2018) The spread and evolution of rabies virus: conquering new frontiers, Nature Reviews Microbiology 16, 241.

[61] Calisher, C. H., Childs, J. E., Field, H. E., Holmes, K. V., and Schountz, T. (2006) Bats: important reservoir hosts of emerging viruses, Clinical microbiology reviews 19, 531-545.

[62] Kumar, H., Kawai, T., and Akira, S. (2011) Pathogen recognition by the innate immune system, International reviews of immunology 30, 16-34.

[63] Schoggins, J. W. (2014) Interferon-stimulated genes: roles in viral pathogenesis, Current Opinion in Virology 6, 40-46.

[64] Banerjee, A., Baker, M. L., Kulcsar, K., Misra, V., Plowright, R., and Mossman, K. (2020) Novel Insights Into Immune Systems of Bats, Front Immunol 11, 26.

[65] Xie, J., Li, Y., Shen, X., Goh, G., Zhu, Y., Cui, J., Wang, L.-F., Shi, Z.-L., and Zhou, P. (2018) Dampened STING-dependent interferon activation in bats, Cell host \& microbe 23, 297-301. e294.

[66] Ahn, M., Cui, J., Irving, A. T., and Wang, L.-F. (2016) Unique loss of the PYHIN gene family in bats amongst mammals: implications for inflammasome sensing, Scientific reports 6, 1-7.

[67] Schountz, T., Baker, M. L., Butler, J., and Munster, V. (2017) Immunological control of viral infections in bats and the emergence of viruses highly pathogenic to humans, Frontiers in immunology 8, 1098. 
[68] Brook, C. E., Boots, M., Chandran, K., Dobson, A. P., Drosten, C., Graham, A. L., Grenfell, B. T., Müller, M. A., Ng, M., and Wang, L.-F. (2020) Accelerated viral dynamics in bat cell lines, with implications for zoonotic emergence, eLife 9.

[69] Anthony, S. J., Johnson, C. K., Greig, D. J., Kramer, S., Che, X., Wells, H., Hicks, A. L., Joly, D. O., Wolfe, N. D., and Daszak, P. (2017) Global patterns in coronavirus diversity, Virus evolution 3.

[70] Lelli, D., Papetti, A., Sabelli, C., Rosti, E., Moreno, A., and Boniotti, M. B. (2013) Detection of coronaviruses in bats of various species in Italy, Viruses 5, 2679-2689.

[71] Monchatre-Leroy, E., Boué, F., Boucher, J.-M., Renault, C., Moutou, F., Ar Gouilh, M., and Umhang, G. (2017) Identification of alpha and beta coronavirus in wildlife species in France: bats, rodents, rabbits, and hedgehogs, Viruses 9, 364.

[72] Annan, A., Baldwin, H. J., Corman, V. M., Klose, S. M., Owusu, M., Nkrumah, E. E., Badu, E. K., Anti, P., Agbenyega, O., and Meyer, B. (2013) Human betacoronavirus 2c EMC/2012-related viruses in bats, Ghana and Europe, Emerging infectious diseases 19, 456.

[73] Goffard, A., Demanche, C., Arthur, L., Pinçon, C., Michaux, J., and Dubuisson, J. (2015) Alphacoronaviruses detected in french bats are phylogeographically linked to coronaviruses of european bats, Viruses 7, 6279-6290.

[74] Tsoleridis, T., Onianwa, O., Horncastle, E., Dayman, E., Zhu, M., Danjittrong, T., Wachtl, M., Behnke, J. M., Chapman, S., and Strong, V. (2016) Discovery of novel alphacoronaviruses in European rodents and shrews, Viruses $8,84$.

[75] Lau, S. K., Woo, P. C., Yip, C. C., Fan, R. Y., Huang, Y., Wang, M., Guo, R., Lam, C. S., Tsang, A. K., and Lai, K. K. (2012) Isolation and characterization of a novel Betacoronavirus subgroup A coronavirus, rabbit coronavirus HKU14, from domestic rabbits, Journal of virology 86, 54815496.

[76] Corman, V. M., Kallies, R., Philipps, H., Göpner, G., Müller, M. A., Eckerle, I., Brünink, S., Drosten, C., and Drexler, J. F. (2014) Characterization of a novel betacoronavirus related to middle East respiratory syndrome coronavirus in European hedgehogs, Journal of virology 88, 717-724.

[77] Hahn, B. H., Shaw, G. M., De Cock, K. M., and Sharp, P. M. (2000) AIDS as a zoonosis: scientific and public health implications, Science 287, 607-614.

[78] Barre-Sinoussi, F., Chermann, J. C., Rey, F., Nugeyre, M. T., Chamaret, S., Gruest, J., Dauguet, C., Axler-Blin, C., Vezinet-Brun, F., Rouzioux, C., Rozenbaum, W., and Montagnier, L. (1983) Isolation of a T-lymphotropic retrovirus from a patient at risk for acquired immune deficiency syndrome (AIDS), Science 220, 868-871.

[79] Plowright, R. K., Field, H. E., Smith, C., Divljan, A., Palmer, C., Tabor, G., Daszak, P., and Foley, J. E. (2008) Reproduction and nutritional stress are risk factors for Hendra virus infection in little red flying foxes (Pteropus scapulatus), Proceedings of the Royal Society B: Biological Sciences 275, 861-869.

[80] Davy, C. M., Donaldson, M. E., Subudhi, S., Rapin, N., Warnecke, L., Turner, J. M., Bollinger, T. K., Kyle, C. J., Dorville, N. A.-Y., and Kunkel, E. L. (2018) White-nose syndrome is associated with increased replication of a naturally persisting coronaviruses in bats, Scientific reports 8, 1-12.

[81] Häsler, B., Gilbert, W., Jones, B. A., Pfeiffer, D. U., Rushton, J., and Otte, M. J. (2012) The economic value of One Health in relation to the mitigation of zoonotic disease risks, In One Health: The Human-Animal-Environment Interfaces in Emerging Infectious Diseases, pp 127-151, Springer.

[82] Salyer, S. J., Silver, R., Simone, K., and Behravesh, C. B. (2017) Prioritizing zoonoses for global health capacity building - themes from One Health zoonotic disease workshops in 7 countries, 2014-2016, Emerging infectious diseases 23, S55.

[83] Yang, Y., Peng, F., Wang, R., Guan, K., Jiang, T., Xu, G., Sun, J., and Chang, C. (2020) The deadly coronaviruses: The 2003 SARS pandemic and the 2020 novel coronavirus epidemic in China, Journal of Autoimmunity, 102434.

[84] Wu, D., Wu, T., Liu, Q., and Yang, Z. (2020) The SARS-CoV-2 outbreak: what we know, International Journal of Infectious Diseases. 
[85] Kampf, G., Todt, D., Pfaender, S., and Steinmann, E. (2020) Persistence of coronaviruses on inanimate surfaces and its inactivation with biocidal agents, Journal of Hospital Infection.

[86] Yeo, C., Kaushal, S., and Yeo, D. (2020) Enteric involvement of coronaviruses: is faecal-oral transmission of SARS-CoV-2 possible?, The Lancet Gastroenterology \& Hepatology.

[87] Sickbert-Bennett, E. E., Weber, D. J., Gergen-Teague, M. F., Sobsey, M. D., Samsa, G. P., and Rutala, W. A. (2005) Comparative efficacy of hand hygiene agents in the reduction of bacteria and viruses, American journal of infection control 33, 67-77.

[88] Yang, C., and Wang, J. (2020) A mathematical model for the novel coronavirus epidemic in Wuhan, China, Mathematical Biosciences and Engineering 17, 2708.

[89] Cao, Z., Zhang, Q., Lu, X., Pfeiffer, D., Jia, Z., Song, H., and Zeng, D. D. (2020) Estimating the effective reproduction number of the 2019-nCoV in China, medRxiv.

[90] Zhou, Y., Vedantham, P., Lu, K., Agudelo, J., Carrion, R., Jr., Nunneley, J. W., Barnard, D., Pohlmann, S., McKerrow, J. H., Renslo, A. R., and Simmons, G. (2015) Protease inhibitors targeting coronavirus and filovirus entry, Antiviral Res 116, 76-84.

[91] Kawase, M., Shirato, K., van der Hoek, L., Taguchi, F., and Matsuyama, S. (2012) Simultaneous treatment of human bronchial epithelial cells with serine and cysteine protease inhibitors prevents severe acute respiratory syndrome coronavirus entry, J Virol 86, 6537-6545.

[92] Yamamoto, M., Matsuyama, S., Li, X., Takeda, M., Kawaguchi, Y., Inoue, J.-i., and Matsuda, Z. (2016) Identification of nafamostat as a potent inhibitor of Middle East respiratory syndrome coronavirus $S$ protein-mediated membrane fusion using the split-protein-based cell-cell fusion assay, Antimicrobial agents and chemotherapy 60, 6532-6539.

[93] He, Y., Li, J., Heck, S., Lustigman, S., and Jiang, S. (2006) Antigenic and immunogenic characterization of recombinant baculovirus-expressed severe acute respiratory syndrome coronavirus spike protein: implication for vaccine design, Journal of virology 80, 5757-5767.

[94] Lin, J., Zhang, J.-S., Su, N., Xu, J.-G., Wang, N., Chen, J.-T., Chen, X., Liu, Y.-X., Gao, H., and Jia, Y.P. (2007) Safety and immunogenicity from a phase I trial of inactivated severe acute respiratory syndrome coronavirus vaccine, Antiviral therapy 12, 1107.

[95] Fine, P., Eames, K., and Heymann, D. L. (2011) "Herd immunity": a rough guide, Clinical infectious diseases 52, 911-916.

[96] Jauregui, A. R., Savalia, D., Lowry, V. K., Farrell, C. M., and Wathelet, M. G. (2013) Identification of residues of SARS-CoV nsp1 that differentially affect inhibition of gene expression and antiviral signaling, PloS one 8.

[97] Zhou, P., Tachedjian, M., Wynne, J. W., Boyd, V., Cui, J., Smith, I., Cowled, C., Ng, J. H., Mok, L., and Michalski, W. P. (2016) Contraction of the type I IFN locus and unusual constitutive expression of IFN- $\alpha$ in bats, Proceedings of the National Academy of Sciences 113, 2696-2701.

[98] Cinatl Jr, J., Michaelis, M., Scholz, M., and Doerr, H. W. (2004) Role of interferons in the treatment of severe acute respiratory syndrome, Expert opinion on biological therapy 4, 827-836.

[99] Loutfy, M. R., Blatt, L. M., Siminovitch, K. A., Ward, S., Wolff, B., Lho, H., Pham, D. H., Deif, H., LaMere, E. A., and Chang, M. (2003) Interferon alfacon-1 plus corticosteroids in severe acute respiratory syndrome: a preliminary study, Jama 290, 3222-3228.

[100] Basler, C. F., Wang, X., Mühlberger, E., Volchkov, V., Paragas, J., Klenk, H.-D., García-Sastre, A., and Palese, P. (2000) The Ebola virus VP35 protein functions as a type I IFN antagonist, Proceedings of the National Academy of Sciences 97, 12289-12294.

[101] Kühl, A., and Pöhlmann, S. (2012) How Ebola virus counters the interferon system, Zoonoses and public health 59, 116-131.

[102] Konde, M. K., Baker, D. P., Traore, F. A., Sow, M. S., Camara, A., Barry, A. A., Mara, D., Barry, A., Cone, M., and Kaba, I. (2017) Interferon $\beta$-1a for the treatment of Ebola virus disease: a historically controlled, single-arm proof-of-concept trial, PloS one 12, e0169255.

[103] Boriskin, Y. S., Pécheur, E.-I., and Polyak, S. J. (2006) Arbidol: a broad-spectrum antiviral that inhibits acute and chronic HCV infection, Virology journal 3, 56. 
[104] Glushkov, R., Gus' kova, T., Krylova, L., and Nikolaeva, I. (1999) Mechanisms of arbidole's immunomodulating action, Vestnik Rossiiskoi akademii meditsinskikh nauk, 36-40.

[105] Pecheur, E.-I., Lavillette, D., Alcaras, F., Molle, J., Boriskin, Y. S., Roberts, M., Cosset, F.-L., and Polyak, S. J. (2007) Biochemical mechanism of hepatitis $C$ virus inhibition by the broadspectrum antiviral arbidol, Biochemistry 46, 6050-6059.

[106] Leneva, I., Burtseva, E., Yatsyshina, S., Fedyakina, I., Kirillova, E., Selkova, E., Osipova, E., and Maleev, V. (2016) Virus susceptibility and clinical effectiveness of anti-influenza drugs during the 2010-2011 influenza season in Russia, International Journal of Infectious Diseases 43, 7784.

[107] Pécheur, E.-I., Borisevich, V., Halfmann, P., Morrey, J. D., Smee, D. F., Prichard, M., Mire, C. E., Kawaoka, Y., Geisbert, T. W., and Polyak, S. J. (2016) The synthetic antiviral drug arbidol inhibits globally prevalent pathogenic viruses, Journal of virology 90, 3086-3092.

[108] Hulseberg, C., Fénéant, L., Szymańska-de Wijs, K., Kessler, N., Nelson, E., Shoemaker, C., Schmaljohn, C., Polyak, S., and White, J. (2019) Arbidol and other low-molecular-weight drugs that inhibit Lassa and Ebola viruses, Journal of virology 93, e02185-02118.

[109] Lu, H. (2020) Drug treatment options for the 2019-new coronavirus (2019-nCoV), Bioscience trends.

[110] Paget, J., Spreeuwenberg, P., Charu, V., Taylor, R. J., Iuliano, A. D., Bresee, J., Simonsen, L., and Viboud, C. (2019) Global mortality associated with seasonal influenza epidemics: New burden estimates and predictors from the GLaMOR Project, Journal of global health 9.

[111] Rasmussen, A. L. (2016) Host factors in Ebola infection, Annual review of genomics and human genetics 17, 333-351.

[112] Keita, A. K., Vidal, N., Toure, A., Diallo, M. S. K., Magassouba, N. f., Baize, S., Mateo, M., Raoul, H., Mely, S., and Subtil, F. (2019) A 40-Month Follow-Up of Ebola Virus Disease Survivors in Guinea (PostEbogui) Reveals Long-Term Detection of Ebola Viral Ribonucleic Acid in Semen and Breast Milk, In Open Forum Infectious Diseases, p ofz482, Oxford University Press US.

[113] Fischer, W. A., Brown, J., Wohl, D. A., Loftis, A. J., Tozay, S., Reeves, E., Pewu, K., Gorvego, G., Quellie, S., and Cunningham, C. K. (2017) Ebola virus ribonucleic acid detection in semen more than two years after resolution of acute Ebola virus infection, In Open forum infectious diseases, $\mathrm{p}$ ofx155, Oxford University Press US.

[114] Carod-Artal, F. J. (2015) Post-Ebolavirus disease syndrome: what do we know?, Taylor \& Francis.

[115] Shantha, J. G., Crozier, I., and Yeh, S. (2017) An update on ocular complications of Ebola virus disease, Current opinion in ophthalmology 28, 600. 